\title{
Perancangan Aplikasi Pendataan Pelanggan pada Perusahaan PT. Indomobil Trada Nasional
}

\author{
Ambar Tri Hapsari ${ }^{1}$, Aswin Fitriansyah ${ }^{2}$ \\ 1,2Informatika, Universitas Indraprasta Jakarta, Indonesia \\ e-mail: 1ambar.trihapsari@gmail.com, ${ }^{2}$ aswin.fitriansyah@gmail.com \\ Submitted Date: November $15^{\text {th }}, 2020$ \\ Reviewed Date: December $30^{\text {th }}, 2020$ \\ Revised Date: December $30^{\text {th }}$, 2020 \\ Accepted Date: January $05^{\text {th }}, 2021$
}

\begin{abstract}
PT Indomobil Sukses International Tbk. (The Company) is the main company of the automotive group of companies. This company has many well-known automotive subsidiaries in Indonesia. This automotive company attaches great importance to products to meet customer needs and satisfaction. Guaranteed quality standards are the company's principle by supporting after-sales service in the $3 \mathrm{~S}$ network (Sales, Service, and Spare parts) that already exist throughout Indonesia. The target of this company's business process must optimize customer data so that the company's target is not difficult to achieve in order to compete with other companies that have used computerized systems. Based on the description, the theme of research on designing customer data collection applications at PT. Indomobil Trada Nasional.
\end{abstract}

Keywords: Pelanggan; Database; Indomobile Trada Nasional; Application

\begin{abstract}
Abstrak
PT Indomobil Sukses Internasional Tbk. (Perseroan) adalah perusahaan utama kelompok perusahaan bidang otomotif. Perusahaan ini mempunyai banyak anak perusahaan bidang otomotif sudah terkenal di Indonesia. Perusahaan otomotif ini sangat mementingkan produk untuk memenuhi kebutuhan dan kepuasan pelanggan. Standar kualitas sudah terjamin merupakan pronsip perusahaan dengan mendukung pelayanan purna jual dalam jaringan 3S (Sales, Service, dan Spare parts) sudah ada di seluruh Indonesia. Target dari proses bisnis perusahaan ini harus mengoptimalkan data pelanggan sehingga target perusahaan tidak sulit tercapai agar dapat berkompetisi sesama perusahaan yang sudah menggunakan komputerisasi pada sistemnya. Bedasarkan uraian tersebut menjadi tema pada penelitian perancangan aplikasi pendataan pelanggan pada perusahaan PT. Indomobil Trada Nasional.
\end{abstract}

Kata Kunci: Pelanggan; Database; Indomobile Trada Nasional; Aplikasi

\section{Pendahuluan}

PT Indomobil Sukses Internasional Tbk. (Perseroan) adalah perusahaan utama kelompok perusahaan bidang otomotif. Perusahaan ini didirikan pada tahun 1976 dan diberi nama PT Indomobil Investment Corporation. Tahun 1997 terjadi penggabungan usaha (merger) dengan PT lndomulti Inti lndustri Tbk. Kemudian nama perusahaan menjadi PT lndomobil Sukses Internasional Tbk. Berkantor pusat di Wisma Indomobil I, Lantai 6, Jl. MT. Haryono Kav. 8, Jakarta Timur - 13330. Perseroan ini bergerak di bidang usaha meliputi: memegang lisensi merek, penjualan kendaraan, kredit kendaraan, penjualan kendaraan lama, penjualan suku cadang, modifikasi kendaraan, peryewaan kendaraan.

Produk-produk yang ada dipersiapkan untuk keperluan pelanggan. Produk yang disediakan dengan standar kualitas terjamin merupakan prinsip perusahaan (Wahyuni, 2008). Dukungan pelayanan purna jual bagus melalui jaringan Sales, Service, dan Spare parts di seluruh Indonesia. Melalui anak perusahaan pemegang lisensi merkmerk terkenal seperti Audi, Foton, Datsun, Hino, Infiniti, Manitou, Suzuki, Volkswagen, Volvo Trucks dan Zoomlion, Volvo Construction Equipment. 
Semua jenis produk kendaraan baik kendaraan motor atau kendaraan mobil dan alat berat. Semua bersinergi menjadi satu sistem sehingga menjadi besar. Seluruh karyawan perusahaan ini di seluruh anak perusahaan di Indonesia berhasil membuat perusahaan menjadi besar (Umar, 2005). Kontribusi positif dari semua karyawan perusahaan menjadi memberikan dampak positif bagi perkembangan perusahaan. Perusahaan memberikan pelatihan, program konseling, kegiatan seminar juga praktek kerja lapangan. Kompetensi untuk mendapatkan jenjang karir di perusahaan ini menjadi prioritas kegiatan perseroan. Kegiatan ini sudah diprogram menjadi sistem dan dievaluasi berkelanjutan (Kotler \& Keller, 2009).

Teknologi informasi terus berkembang, khususnya teknologi informasi basis komputer di mana awalnya digunakan orang-orang atau perusahaan tertentu saja (Aaker, 2013). Kebutuhan akan teknologi dan informasi sangat tinggi untuk membantu berbagai jenis bidang pekerjaan manusia (Taufiq, et al., 2020). Teknologi komputer sudah banyak digunakan dalam berbagai bidang kegiatan bisnis seperti bidang industri, pemerintahan, perbankkan dan bidang akademik.

Teknologi informasi ditujukan untuk membantu pekerjaan dalam pengolahan dan penyediaan informasi (Hanum \& Saifudin, 2019). Perkembangan teknologi informasi inilah yang mengakibatkan pergeseran standar efektifitas suatu perusahaan. Efektifitas suatu perusahaan sangat diperlukan untuk kemajuan perusahaan tersebut (Kotler, et al., 2010). Hal ini diimbangi dengan kebutuhan informasi yang mudah didapat dengan cepat dan berdaya guna. Sebuah sistem infornasi yang didukung oleh perangkat keras dan perangkat lunak yang handal. Peralihan sistem tertulis dengan sistem berbasis komputer.

Beralihnya sistem tersebut untuk masa sekarang ini sangat diperlukan, karena hampir setiap perusahaan menggunakan sistem secara terkomputerisasi (Sudana, 2013). Perusahaan dengan sekala kecil juga dapat menggunakan sistem terkomputerisasi (Kasmir, 2014). Dengan sistem tertulis perusahaan tidak bisa berjalan dengan optimal sehingga target pcrusahaan sulit tercapai, karena sangat sulit untuk bersaing dengan perusahaan lain yang sudah lebih dulu menggunakan sistem komputerisasi. Bedasarkan uraian tersebut menjadi tema pada penelitian perancangan aplikasi pendataan kastemer pada perusahaan PT. Indomobil Trada Nasional.
Berdasarkan latar belakang di atas, adapun identifikasi masalah yang dapat dirumuskan, antara lain: Sistem yang digunakan masih manual, sehingga proses pengolahan data tidak akurat. Lambatnya penyampaian informasi yang diterima. Data yang diterima kurang efisien dan efektif dalam penggunaannya. Penelitian ini dilakukan adalah untuk mengetahui sistem yang digunakan untuk mengolah data-data pelanggan pada unit kerja yang ada pada PT. Indomobil, memberikan suatu perancangan aplikasi yang terkomputerisasi dan kendala yang dihadapi dalam penerapan sistem tersebut.

\section{Metodologi}

Proses pengumpulan data adalah kegiatan paling strategis dalan penelitian, karena mendapatkan data merupakan tujuan utama dari penelitian (Sugiyono, 2013). Penelitian ini dilakukan untuk membuat aplikasi pendataan pelanggan yang digunakan untuk melakukan pendataan di PT. Indomobil sehingga dapat diakses oleh semua unit kerja yang ada pada PT. Indomobil. Ada beberapa metode penelitian (Sugiyono, 2008), yaitu:

a. Metode Pengamatan Langsung (Observasi)

Merupakan pengamatan langsung menjadi salah satu teknik pengumpulan data dangat efektif dalam mempelajari sistem. Kegiatan pengamatan langsung oleh peneliti terhadap kegiatan riset pada PT. Indomobil.

b. Metode Wawancara

Peneliti memperoleh keterangan dengan cara tanya jawab dengan tatap muka secara langsung dengan pihak-pihak yang berkaitan langsung ataupun tidak langsung di dalam proses pendaftaran pelanggan bulanan PT Indomobil.

c. Metode Studi Pustaka (Library Search) Peneliti mencai infonnasi dari buku-buku, literatur, dan surnber- surnber lain yang berkaitan dengan penelitian ini.

\section{Proses Bisnis}

Proses bisnis sistem berjalan pada PT. Indomobil Trada Nasional adalah sebagai berikut:

a. Bagian penjualan atau sales and marketing supervisor menerima Purchase Order (PO) dari pelanggan.

b. Setelah PO diterima, bagian penjualan mengeluarkan surat pesanan barang kepada bagian maintenance untuk mengecek stock barang 
c. Surat pesaanan barang yang diterima oleh bagian maintanance digunakan juga untuk melihat stock yang ada sesuai dengan surat pesanan barang atau tidak, ini akan ada dua kemungkinan yaitu:

d. Stock memenuhi pesanan

1. Bagian maintenance mengeluarkan delivery order (DO) jumlah harus sesuai dengan jumlah pesanan barang

2. DO diserahkan pada bagian gudang berdasarkan do yang diterima maka bagian gudang menerbitkan bukti pengeluaran barang.

3. Bagian gudang menyiapkan barang dan mengecek ulang sebelum dikirim

4. Berdasakan bukti pengeluaran barang maka accounting menerbitkan invoice

5. Barang siap dikirim disertai dengan do dan invoice

6. Semua transaksi tersebut yang berlangsung dilaporkan pada kepala gudang, dan accounting.

e. Stock tidak ada

1. Bagian pembelian mengeluarkan purchase order (PO) untuk pemesanan barang

2. Bila pesanan barang telah ada maka bagian gudang menerima barang dan diperiksa sesuai dengan PO dan surat jalan yang diterima

3. Setelah barang diterima sudah menjadi stock pada bagian maintenance dan proses pengiriman mengikuti langkah-langkah yang ada pada stock memenuhi pesanan.

\section{Aturan Bisnis Sistem yang Diusulkan}

Diagram alir data pada suatu sistem menggambarkan proses yang terjadi pada sistem yang sedang berjalan pada saat ini. Diagram ini menggambarkan proses dilakukan oleh aturan bisnis sistem. Perusahaan melakukan pendataan pelanggan pada PT. Indomobil Trada Nasional ada sejumlah prosedur wajib dijalankan dalam setiap kegiatan. Proses analisa aturan bisnis pendataan konsumen pada PT. Indomobil Trada Nasional berikut ini adalah:

a. Kebutuhan pendataan konsumen yang diajukan oleh unit kerja kepada kepala bagian penjualan segera dipenuhi apabila konsumen tersebut membeli sebuah mobil.

b. Mobil yang diterima oleh konsumen adalah milik PT. Indomobil dan harus dibukukan dalam buku pendataan konsumen. c. Mobil yang sudah diserahkan atau dibeli konsumen adalah menjadi milik konsumen untuk dikelola dan dipergunakan secara baik.

\section{Dekomposisi Fungsi Sistem}

Sistem pendataan pelanggan pada PT. Indomobil Trada Nasional melalui beberapa proses yaitu:

a. Proses pemesanan mobil, Pertama-tama bagian gudang memeriksa stok barang yang ada digudang. Apabila ada permintaan dari unit kerja dan stok barang kosong maka bagian Gudang melakukan pemesanan barang kepada supplier.

b. Proses penerimaan barang, Data barang pesanan yang dibutukhan diserahkan kepada supplier untuk dipenuhi. Setelah itu supplier menyerahkan barang yang dibutuhkan unit kerja kepada bagian gudang. Kemudian bagian gudang menerirna barang tersebut dan melakukan pengecekan barang.

c. Proses pembayaran, Apabila barang telah diterima maka proses selanjutnya adalah bagian keuangan membayar barang-barang kebutuhan tersebut kepada supplier. Setelah itu supplier memberikan faktur pembelian barang kepada bagian Manager sebagai tanda bukti pembayaran.

d. Proses pembuatan laporan, Setelah selesai melakukan pengadaan barang, maka bagian gudang dan bagian keuangan akan membuat laporan bulanan untuk dilaporkan kepada General Manager guna mengambil kebijakankebijakan selanjutnya.

\section{Analisa Proses}

Rancangan proses pendataan pelanggan yang dimasukan ini dapat dideskripsikan sebagai berikut: Proses pendataan pelanggan pada PT. Indomobil Trada Nasional dimulai dari bagian penjualan/sales menerima PO dari pelanggan, berdasarkan PO tersebut penjualan tersebut diberikan ke maintenance setelah melalui prose pengecekan. Dimana setelah proses tersebut maintenance mendapat informasi persediaan barang didapat maka ada dua kemungkinan. Jika persediaan memenuhi pesanan pelanggan maka bagian maintenance mengeluarkan Delivery Order kepada bagian maintenance dan barang siap dikirim kepada pelanggan. Jika barang tidak memenuhi pesanan pelanggan maka bagian administrasi Gudang mengeluarkan surat perencanaan pembelian kepada bagian accounting mengeluarkan surat Order Pembelian (PO) untuk 
memesan barang pada pemasok. Dari pemasok memberikan surat pengiriman pembelian ke bagian penerimaan. Jika pengiriman barang dari pemasok sesuai dengan pesanan maka barang diteruskan kebagian Gudang, dan penerimaan barang tersebut diinformasikan kebagian maintenance sehingga dapat dilanjutkan proses pengiriman barang tersebut kepada pelanggan.

\section{Diagram Aliran Data (DAD)}

Berikut ini adalah gambaran secara logika dengan menggunakan Diagram Aliran Data. Diagram ini menggambarkan proses bisnis pada sistem PT. Indomobil.

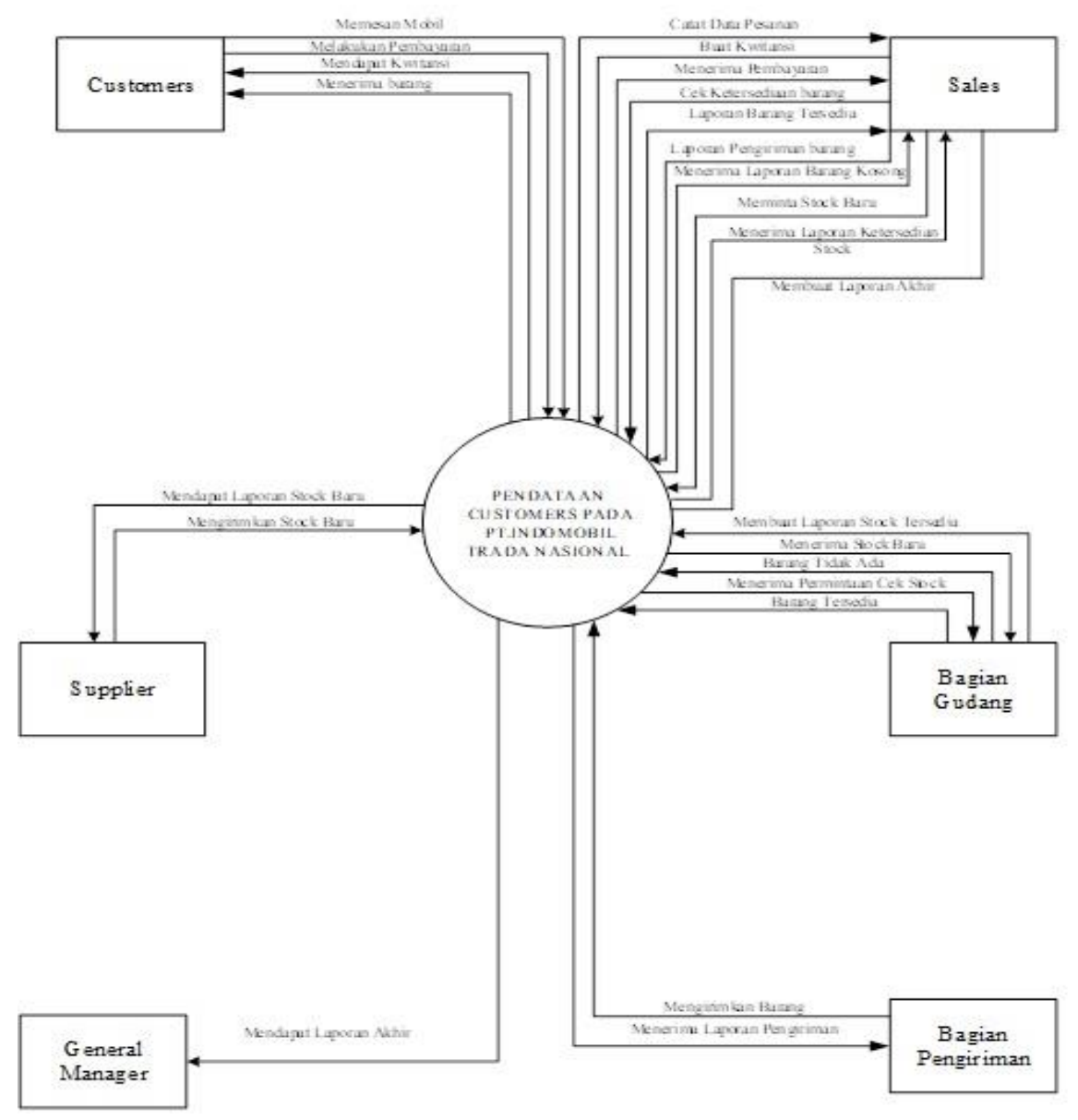

Gambar 1 Diagram Aliran Data IndoMobil

Gambar 1 menjelaskan proses bisnis secara logika bagaimana elemen dari sistem yang ada pada sistem perusahaan PT. Indo Mobil. Setiap eleman tersebut saling berhubungan dan berinteraksi mengirim data secara timbal balik.

\section{Diagram Konteks}

Berikut ini merupakan gambaran tentang sistem yang diusulkan pada pendataan pelanggans pada PT. Indomobil Trada Nasional dalam bentuk Diagram Konteks, yang menggambarkan proses tahap-tahap proses dari diagram konteks.
Pada gambar 2 dijelaskan secara logika bagaimana data dapat terbentuk dalam bentuk datastore yang akan ditransformasikan menjadi data komputer dalam bentuk tabel.

\section{Bagan Struktur}

Berikut ini adalah gambaran secara logika tentang struktur menu yang terdapat pada aplikasi yang dibangun dalam penelitian ini untuk digunakan pada system PT. Indomobil. 


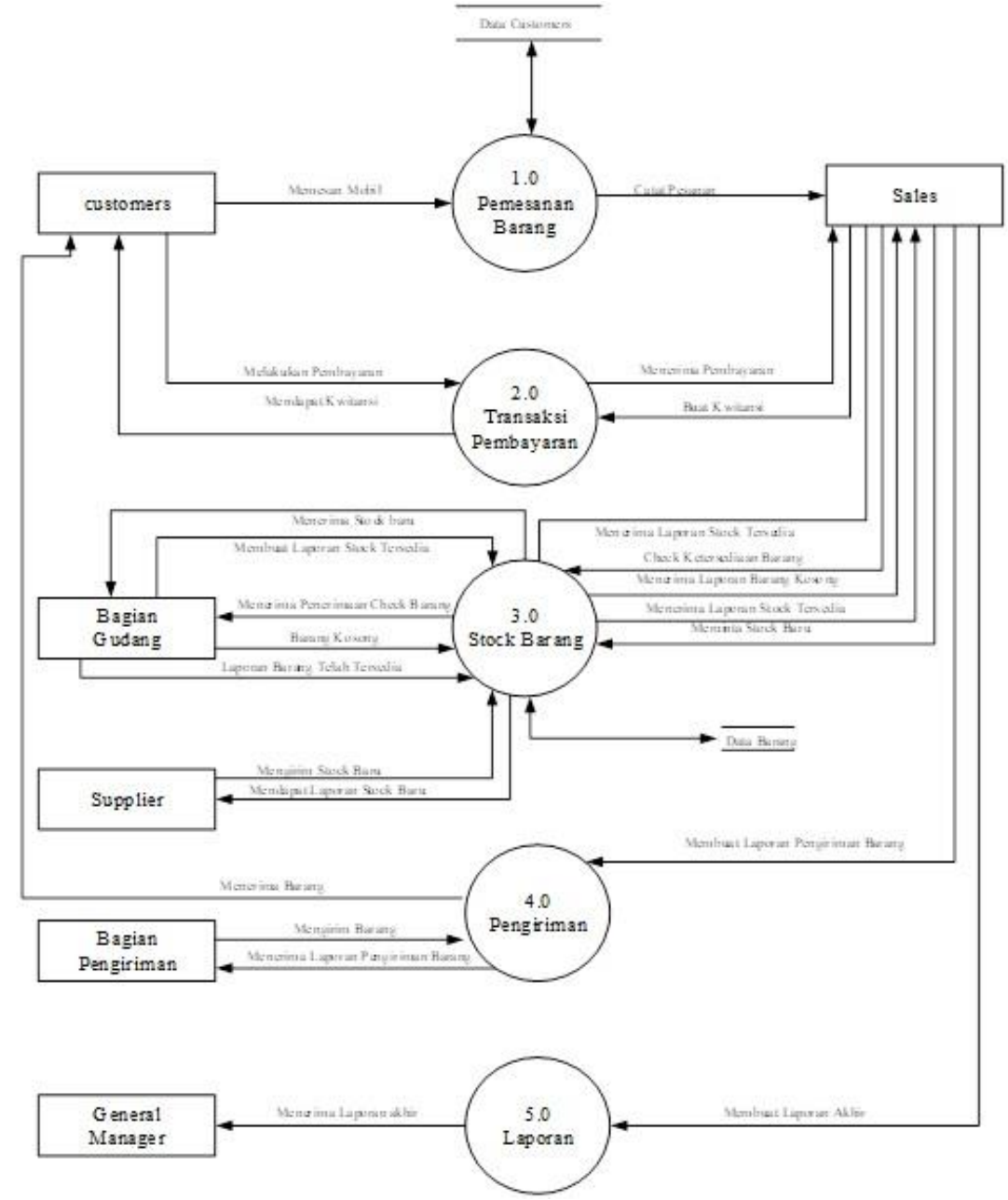

Gambar 2 Diagram Konteks Indomobil

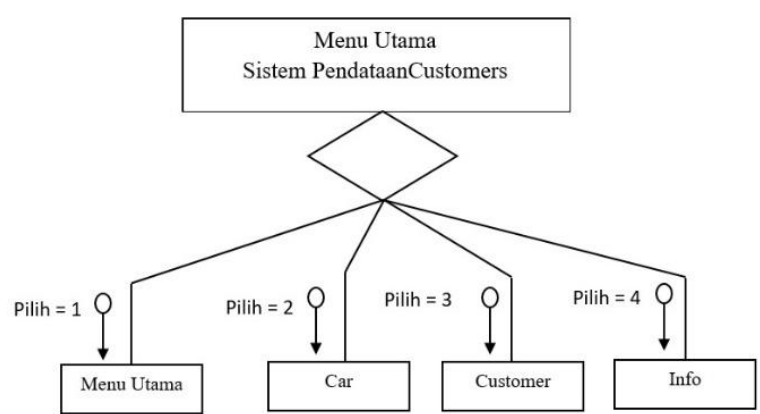

Gambar 3. Bagan Terstuktur Menu Utama
Gambar 3 menjelaskan struktrur dari menu aplikasi yang terbentuk berisi beberapa menu yang masing-masing menu mengolah data sesuai yang terdantum pada menu.

\section{ERD (Entity Relationship Diagram)}

Berikut ini adalah gambaran secara logika tentang database yang terdapat pada system pendataan pelanggan pada sistem di PT. Indomobil yang di gambarkan dalam bentuk diagram ER. 


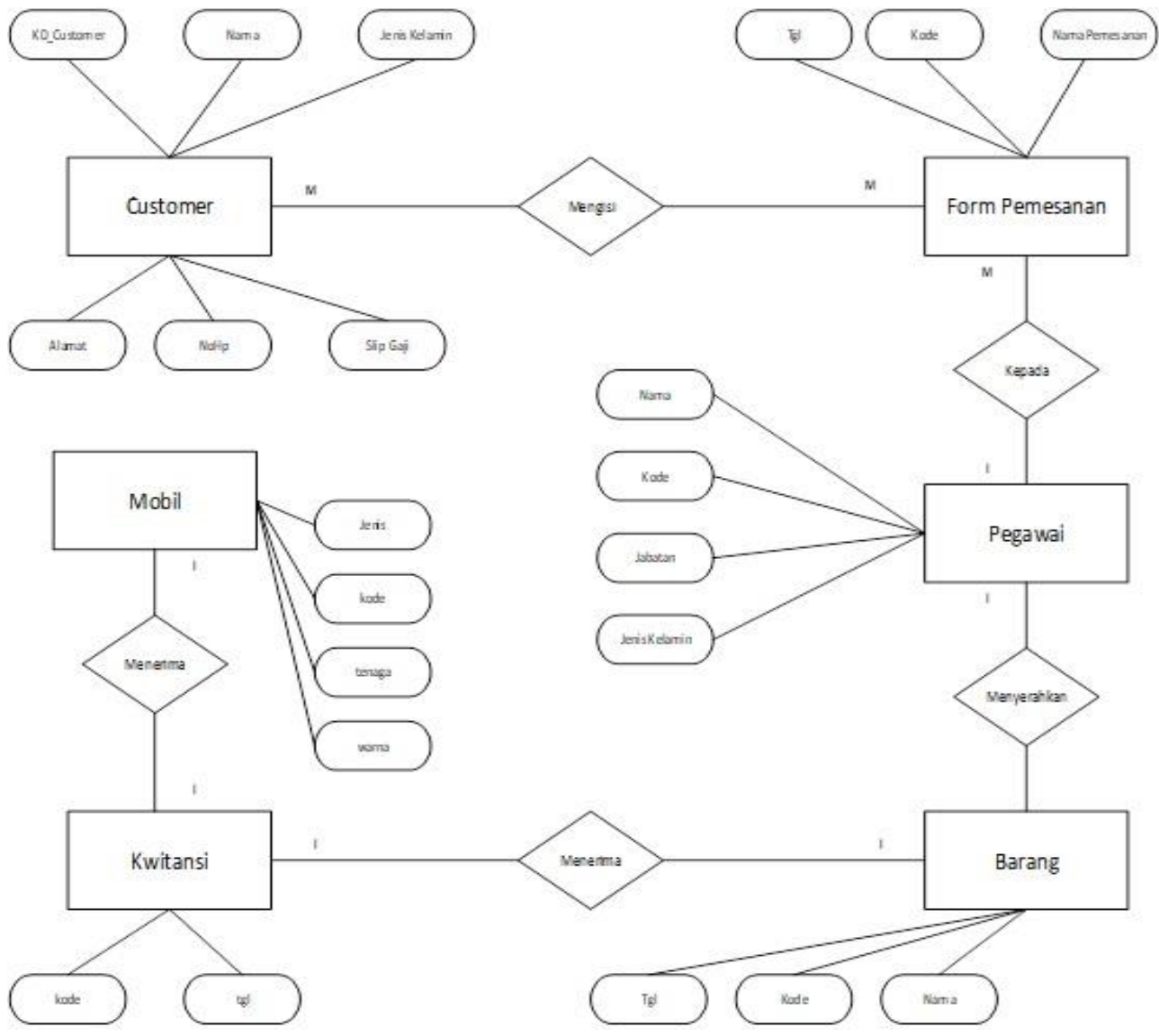

Gambar 4 Diagram ER system PT. Indomobil

Gambar 4 menjelaskan hubungan antara datastore hasil dari proses transformasi diagram Kontak. Setiap datastore mempunyai atribut yang berisi data-data secara detail yang menjadi value dari field pada tabel.

\section{Tampilan Aplikasi Pendataan Pelanggan}

a. Rancangan Layar Utama

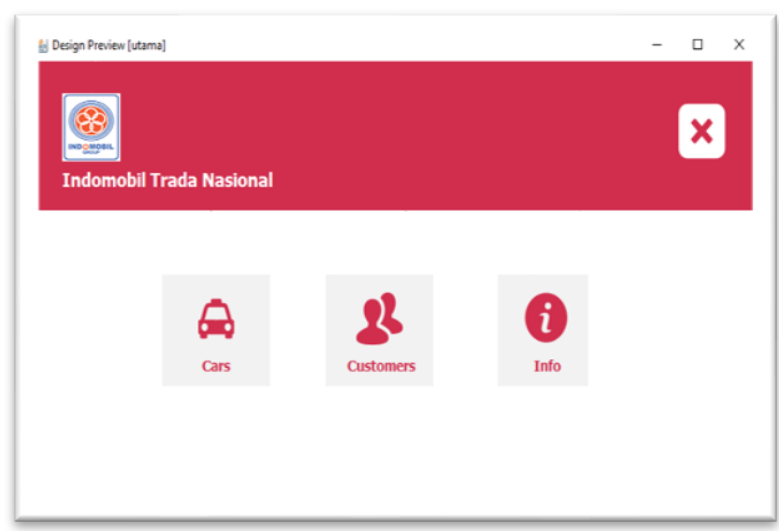

Gambar 5 Perancangan Layar Utama
Pada menu utama, telah disediakan icon untuk memilih ingin mendata pelanggans atau menambahkan produk baru di cars sehingga bila di pilih keluar tampilan inputan pelanggans maupun cars.

b. Rancangan Layar Cars

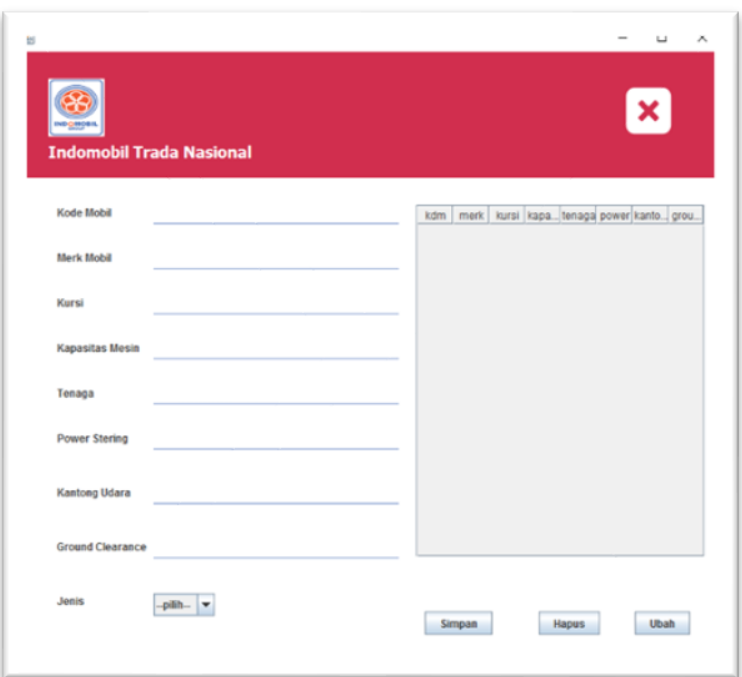

Gambar 6. Perancangan Layar Form Cars 
Pada menu Cars, telah disediakan form untuk menanbahkan data mobil untuk mendata mobil atau menambahkan produk baru di cars sehingga bila dipilih simpan, keluar tampilan table dan tersimpan didatabase.

\section{c. Rancangan Layar Pelanggans}

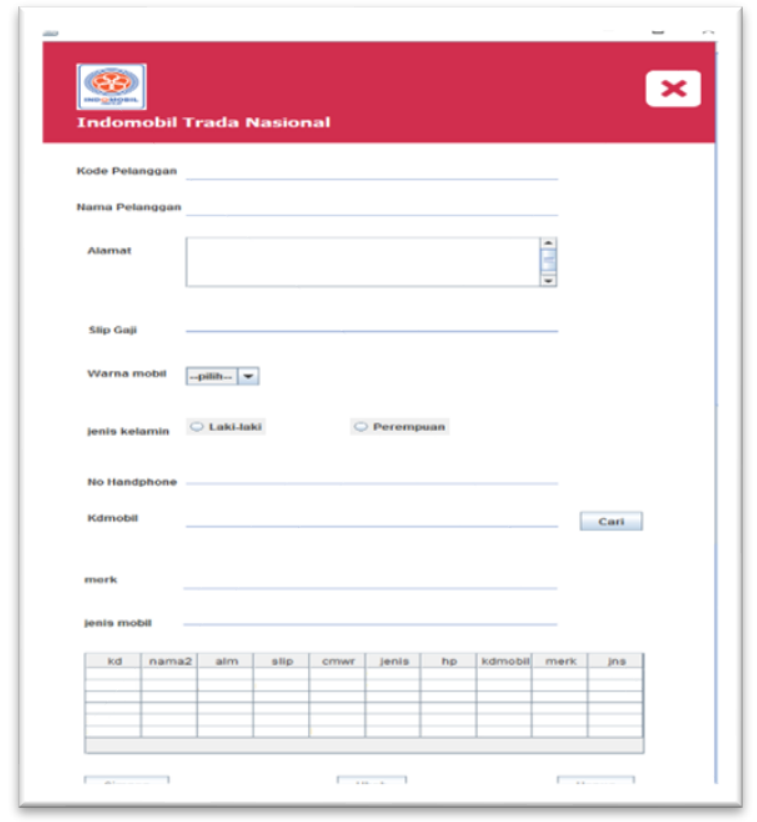

Gambar 7. Percangan Layar Form Pelanggans

Pada menu Pelanggan, telah disediakan form untuk menanbahkan data pelanggan untuk mendata konsumen atau menambahkan konsumen baru di pelanggan sehingga bila dipilih simpan, keluar tampilan table dan tersimpan didatabase.

\section{Simpulan}

Berdasarkan penelitian yang telah dilakukan mengenai sistem pendataan pelanggan pada PT. Indomobil Trada Nasional peneliti menarik kesimpulan bahwa:

a. Dengan adanya sistem yang sudah terkomuputerisasi, maka tingkat efektivitas dan konsisten data terjamin

b. Penyimpanan data lebih efisien, sehingga tidak ada lagi penumpukan data atau arsip yang tampak

c. Memudahkan admin untuk memantau atau mengotrol data yang ada dalam database

d. Laporan keuangan menjadi terperinci dan tidak ada lagi yang tidak tersusun dengan baik,

\section{Saran}

Untuk menunjang kerja kinerja PT. Indomobil Trada Nasional, peneliti mengemukakan saran-saran yang lain. Kiranya dapat membantu dalam sistem pendataan pelanggans, saran-saran tersebut antara lain:

a. Disarankan perusahaan menggunakan sistem yang dirancang ini, agar masalah-masalah yang ada sekarang ini pada sistem pendataan pelanggan

b. dapat diatasi dengan baik dan perlu dikembangkan lagi dimas mendatang sesuai dengan kemajuan teknologi.

c. Memerlukan sumber daya manusia yang berkualitas baik untuk mengelola dan memelihara sistem. Sistemnya baik maupun sumber daya manusiannya rendah maka hal tersebut sia-sia. Harus diadakan latihan kepada seluruh staff Gedung.

d. Tindakan pengamanan perlu dilakukan karena computer adalah alat yang sangat peka, maka keberadaanya harus dijaga dengan baik dan terawat. Resiko kehilangan data dan rusaknya data harus diantisipasi dengan cara membackup data secara berkala.

e. Memerlukan pengawasan pada penerapan sistem yang baru sehingga bila terdapat kelemahan bisa segera diatasi.

\section{Referensi}

Aaker, D. A., 2013. Manajemen Pemasaran Startegis. Jakarta: Salemba Empat.

Hanum, W. S. \& Saifudin, A., 2019. Rancang Bangun Aplikasi Panduan Pariwisata di Kabupaten Banyuwangi Mobile Berbasis Android. Jurnal Teknologi Sistem Informasi dan Aplikasi, 2(2), pp. 59-65.

Kasmir, 2014. Analisis Laporan Keuangan. s.l.:s.n.

Kotler, P. \& Keller, K. L., 2009. Manajemen Pemasaran. Jakarta: Erlangga.

Kotler, P., K. H. \& Setiawan, I., 2010. Marketing 3.O.. Jakarta: Erlangga.

Sudana, I. M., 2013. Manajemen Keuangan Perusahaan Teori dan Praktek. Jakarta: Erlangga.

Sugiyono, 2008. Metode Penelitian Bisnis. Bandung: Alfabeta.

Sugiyono, 2013. Metode Penelitian Kuantitatif, Kualitatif, dan R\&D.. Bandung: Alfabeta.

Taufiq, R., Magfiroh, D. A., Yusup, D. \& Yulianti, Y., 2020. Analisis dan Desain Sistem Informasi Pembayaran Sumbangan Pembinaan Pendidikan (SPP) di SMK Avicena Rajeg. Jurnal Teknologi Sistem Informasi dan Aplikasi, 3(1), pp. 15-21.

Umar, H., 2005. Riset Pemasaran dan Perilaku Konsumen. Jakarta: PT. Gramedia.

Wahyuni, D. U., 2008. Pengaruh Motivasi, Persepsi dan Sikap Konsumen Terhadap Keputusan Pembelian Sepeda Motor Merek "Honda" di Kawasan Surabaya Barat. Jurnal Manajemen \& Kewirausahaan, pp. Vol. 10, No. 1. 